\title{
A EFICÁCIA NO ORDENAMENTO JURÍDICO PORTU- GUÊS DA DECLARAÇÃO UNIVERSAL DOS DIREITOS DO HOMEM
}

Eduardo Henrique Rodrigues da Cunha Moreira*

Sumário: 1 Introdução; 2 O surgimento da Declaração Universal dos Direitos do Homem; 3 A eficácia na ordem jurídica portuguesa da Declaração Universal dos Direitos do Homem - divergência doutrinária e posição do Tribunal Constitucional; 4 Considerações finais.

Resumo: Este trabalho visa analisar a eficácia da Declaração Universal dos Direitos do Homem (DUDH) no ordenamento jurídico português, abordando-se desde a posição doutrinária mais conservadora - que não atribui aos preceitos da DUDH a natureza de direitos constitucionais -, até a posição doutrinária mais liberal - que atribui à DUDH um valor supraconstitucional. Ao final, é exposta a posição do Tribunal Constitucional português, órgão que tem legitimidade no desenvolvimento do próprio direito constitucional, através da interpretação dada às normas da Constituição pelos juízes constitucionais.

Palavras-chave: Eficácia na ordem jurídica portuguesa da Declaração Universal dos Direitos do Homem. Divergência doutrinária e posição do Tribunal Constitucional. Estatuto constitucional da DUDH.

\footnotetext{
* Advogado inscrito na OAB/MG, mestre em Direito Constitucional pela Faculdade de Direito da Universidade de Coimbra - Portugal; especialista em Direito Constitucional pela Faculdade de Direito da Universidade de Coimbra; especialista em Direito Público e Filosofia do Direito pela Faculdade Católica de Uberlândia e Centro Jurídico Dominis; bacharel em História pela Universidade Federal de Uberlândia - UFU; membro da Associação dos Diplomados da Escola Superior de Guerra - ADESG/Uberlândia - Turma 2006.
} 


\section{Introdução}

Durante quarenta e oito anos, Portugal passou por uma dolorosa experiência com o regime ditatorial, conhecido por Estado Novo, vendo submergirem diversos direitos fundamentais, seja através da via infraconstitucional com as cláusulas de remissão à leis reguladoras do exercício de certos direitos, seja por meio da violação direta dos direitos fundamentais. A Revolução de 25 de abril de 1974 colocaria fim a esse regime opressor, de moldes fascistas, trazendo o estabelecimento de um Estado de Direito Material em que a preocupação maior dos parlamentares constituintes viria a ser a proteção efetiva dos direitos fundamentais, que deveriam emergir da "clausura" em que se encontravam e, "bem ao contrário, [ser arejado] com os ventos das soluções concretas insertas em documentos pertencentes ao Direito Internacional dos Direitos do Homem"'.

Nesse sentido, encontramos no $n^{\circ} 2$ do art. $16^{\circ}$ da Constituição da República Portuguesa (CRP), sob a epígrafe "Sentido dos Direitos Fundamentais", um apelo expresso à DUDH, asseverando que, "os preceitos constitucionais e legais relativos aos direitos fundamentais devem ser interpretados e integrados em harmonia com a Declaração Universal dos Direitos do Homem"². Quando do cinqüentenário da DUDH, o presidente da Assembléia da República portuguesa à época, Antônio de Almeida Santos, chegou a afirmar que Portugal tinha não apenas uma Democracia Política avançada, um Estado de Direito alinhado pelos seus pares europeus, uma Constituição que havia incorporado todos os direitos consagrados na DUDH e outros tantos da mesma família ético-política, como também tinha deixado expresso que esses direitos deviam ser interpretados e integrados de harmonia com aquela Declaração. Almeida Santos conclui sua exposição assegurando que:

“(...) a Portugal, à partida para o inferno da ditadura que durante quase meio século o oprimiu, só mesmo faltava a liberdade de escolher o seu próprio destino para introduzir no seu sistema jurídico-político os Direitos Funda-

\footnotetext{
GOUVEIA, Jorge Bacelar. A Declaração Universal dos Direitos do Homem e a Constituição Portuguesa. In: Revista de Informação Legislativa, Brasília, ano 35, n. 139, jul./set. 1998. p. 262.

2 Art. $16^{\circ}, \mathrm{n}^{\circ} 2$, da CRP, de 25.04.1976. Apesar das sete revisões constitucionais a que o texto inicial da CRP já se submeteu (em 1982, 1989, 1992, 1997, 2001, 2004 e 2005), a única alteração ocorrida, até hoje, no art. $16^{\circ}$, diz respeito à nova epígrafe que a revisão de 1982 lhe trouxe, substituindo a antiga expressão Extensão dos direitos por Âmbito e sentido dos direitos fundamentais.
} 

do homem

mentais que há muito tinha no coração. Esta foi, afinal, a mais significativa homenagem que Portugal prestou aos princípios e valores que a Declaração Universal consagra. ${ }^{3}$

Para Jorge Miranda, a CRP, de 25 de abril de 1976, é a mais vasta e a mais complexa de todas as Constituições portuguesas. É uma Constituiçãogarantia e uma Constituição-prospectiva, oriunda de um ambiente de aversão do passado próximo em que tudo parecia ser possível e que procura "vivificar e enriquecer o conteúdo da democracia, multiplicando as manifestações de igualdade efectiva, participação, intervenção, socialização, numa visão ampla e não sem alguns ingredientes de utopia"4. Entre as marcas de originalidade da CRP, Miranda ressalta a recepção formal da DUDH enquanto critério de interpretação e integração das normas sobre direitos fundamentais.

Logo, a partir desse contexto, dissertaremos sobre a eficácia da DUDH no ordenamento jurídico português. Para tanto, partiremos da posição doutrinária mais conservadora ${ }^{5}$, que não atribui aos preceitos da DUDH a natureza de direitos constitucionais, vendo-os como princípio de interpretação constitucional em matéria de direitos fundamentais, embora o intérprete e aplicador do direito não esteja dispensado da necessidade de recorrer, primeiramente, à ordem constitucional, até chegarmos à posição mais liberal, que assevera que a CRP se auto-subordina à DUDH a nível interpretativo, em matéria de direitos fundamentais, daí decorrendo o valor supraconstitucional da DUDH e, que defende a tese de que, mesmo que a interpretação conforme a DUDH seja menos favorável do que a mera interpretação de normas da CRP, prevalecerá a interpretação menos favorável. Por fim, faremos menção à posição do Tribunal Constitucional português, o órgão "guardião da Constituição" e a quem cabe, efetivamente, a interpretação das normas expressas na Carta Magna. ${ }^{6}$

3 ASSEMBLÉIA da República. Declaração Universal dos Direitos do Homem - 50 anos. Santo Tirso/Portugal: Norprint, 1998. p. 5.

4 MIRANDA, Jorge. A Constituição e a Democracia Portuguesa. Disponível em: <http://www.25abril. org/docs/congresso/democracia/01.01-Jorge\%20Miranda.pdf.> Acesso em: 10 dez. 2007.

5 Gouveia classificaria as duas posições extremas de minimalista (a que chamo de conservadora) e maximalista (liberal nos meus termos). GOUVEIA, Jorge Bacelar, A Declaração Universal dos Direitos do Homem e a Constituição Portuguesa. In: Revista de Informação Legislativa, Brasília, ano 35, n. 139, jul./set. 1998. p. 276.

6 Conforme Canotilho, que assevera que "o Tribunal Constitucional, mesmo primariamente limitado ao controlo jurídico-constitucional das normas jurídicas, excluindo dos seus juízos valorações políticas ou apreciações de mérito político (...), não se pode furtar à tarefa de guardião da Constituição, apreciando a constitucionalidade da política normativamente incorporada em actos dos 
No final do trabalho, esperamos ter conseguido explanar, mesmo que em poucas folhas, sobre as diferentes perspectivas interpretativas do disposto no art. $16^{\circ}, \mathrm{n}^{\circ} 2$, da CRP, tendo condições de posicionarmos à respeito da questão suscitada pelo eminente professor Dr. José Carlos Vieira de Andrade, em sua obra "Os Direitos Fundamentais na Constituição Portuguesa de 1976": quando o art. 16, $\mathrm{n}^{\circ} 2$, da CRP, remete para a DUDH, para efeitos de integração dos preceitos constitucionais nessa matéria, não estaria a constitucionalizar os direitos fundamentais que eventualmente resultem de princípios contidos na Declaração? ${ }^{7}$

\section{O surgimento da Declaração Universal dos Direitos do Homem}

Após a Segunda Guerra Mundial, encontramos em todas as declarações de direitos expressas nas Constituições dos diversos Estados nacionais a consagração de direitos civis, políticos, econômicos e sociais. Assim, tal fato não viria a acontecer de modo diferente quando da elaboração da DUDH, constituída da fusão de concepções liberais ocidentais e socialistas. Entretanto, os países de Leste - África do Sul, Arábia Saudita, Bielo-Rússia, Checoslováquia, Iugoslávia, Polônia, Ucrânia e União Soviética - não ficaram completamente satisfeitos com os preceitos ali introduzidos - especialmente pela mudez desta sobre os direitos dos povos -, abstendo-se voluntariamente da votação final para não a mancharem com votos contrários (48 votos a favor, nenhuma oposição e oito abstenções).

Dessa forma, com participação de todos os países então membros da Organização das Nações Unidas (ONU), a DUDH, de conteúdo abrangente, foi aprovada e proclamada pela Assembléia Geral das Nações Unidas no dia 10 de dezembro de 1948.

órgãos de soberania. (...) Com a garantia da observância das normas constitucionais conexionam-se relevantíssimas questões político-constitucionais como: (...) (4) legitimidade do desenvolvimento do próprio direito constitucional através da interpretação dada às normas da Constituição pelos juízes constitucionais". CANOTILHO, José Joaquim Gomes. Direito Constitucional e Teoria da Constituição. 7. ed. Coimbra: Almedina. p. 681-682. Sobre a competência do Tribunal Constitucional, ver, ainda, COSTA, José Manuel Moreira Cardoso da. A Jurisdição Constitucional em Portugal. 3. ed. Coimbra: Almedina, 2007. p. 29: “O Tribunal Constitucional português é concebido essencialmente como um órgão jurisdicional de controlo normativo - de controlo da constitucionalidade e da legalidade: consoante logo resulta do teor do art. $223^{\circ}, \mathrm{n}^{\circ} 1$, CRP, essa é a sua competência característica e nuclear e a que ditou a sua criação, assumindo as demais um relevo claramente secundário, não obstante a importância de que se revestem. Estas últimas são, não apenas as enunciadas no $\mathrm{n}^{\circ} 2$ do mesmo art. $223^{\circ}$, mais ainda as atribuídas ao Tribunal pelo legislador ordinário".

7 ANDRADE, José Carlos Vieira de. Os Direitos Fundamentais na Constituição Portuguesa de 1976. 3. ed. Coimbra: Almedina, 2007. p. 78. 
A Assembléia Geral da ONU proclama a DUDH como o ideal comum a ser atingido por todos os povos e todas as nações, com o objetivo de que todos os indivíduos e cada órgão da sociedade, tendo-a constantemente no espírito, se esforcem, através do ensino e da educação, por desenvolver o respeito a esses direitos e liberdades e por promover, pela adoção de medidas progressivas de caráter nacional e internacional, o seu reconhecimento e a sua observância universal e efetiva, tanto entre os povos dos próprios Estados-Membros, quanto entre os povos dos territórios sob sua jurisdição.

Em relação ao seu valor jurídico, a DUDH não é um documento que representa obrigatoriedade legal, fonte de obrigações para os Estados, apesar de ser incontestável a sua importância histórica e política. Algumas de suas disposições constituem princípios gerais de Direito ou representam considerações básicas de humanidade. Os princípios proclamados podem ter e têm em sua maior parte, valor de direito costumeiro, mesmo de normas imperativas ${ }^{8}$. Mais tarde, a DUDH serviu como base para os dois tratados sobre direitos humanos da ONU de força legal: o Tratado dos Direitos Civis e Políticos e o Tratado Internacional dos Direitos Econômicos, Sociais e Culturais.

O Guiness Book of World Records traz a DUDH como sendo o documento traduzido no maior número de línguas (aproximadamente 337 no ano de 2008). Em maio de 2009, o sítio oficial da DUDH dava conta da existência de 360 traduções disponíveis.

\footnotetext{
Nesse mesmo sentido, encontra-se o posicionamento de Ian Brownlie, que sobre a DUDH acrescenta: “(...) Talvez a sua maior importância seja a de constituir um guia, da autoria da Assembléia Geral, para uma interpretação autêntica das disposições da Carta. Sem dúvida que existe uma grande área de ambigüidade; porém, o efeito jurídico indirecto da Declaração não deve ser subestimado, sendo frequentemente considerada como uma parte do 'Direito das Nações Unidas'. A Declaração foi invocada pelo Tribunal de Justiça Europeu como um meio complementar à interpretação da Convenção Européia dos Direitos Humanos, e pelo Tribunal Internacional de Justiça em relação à detenção de reféns "em condições de sofrimento"'. BROWNLIE, Ian. Princípios de Direito Internacional Público. Lisboa: Fundação Calouste Gulbenkian, 1997. p. 594. Na mesma linha de raciocínio, ver a posição de Nguyen Quoc Dinh, Patrick Daillier e Alain Pellet, que ainda apresentam um exemplo prático: “(...) no processo do "pessoal diplomático e consular dos Estados Unidos em Teerão', o T.I.J. foi de parecer que 'o fato de privar abusivamente da sua liberdade seres humanos e de os submeter, em condições penosas, a um constrangimento físico é manifestamente incompatível com os princípios da Carta das Nações Unidas e com os direitos fundamentais enunciados na Declaração Universal dos Direitos do Homem”. PELLET, Alain [et al.] Direito Internacional Público. 2. ed. Lisboa: Fundação Calouste Gulbenkian, 2003. p. 675.
} 


\section{A eficácia na ordem jurídica portuguesa da Declaração Univer- sal dos Direitos do Homem - divergência doutrinária e posição do Tribunal Constitucional}

Conforme foi exposto na Introdução, para falarmos sobre a eficácia na ordem jurídica portuguesa da DUDH, discorreremos da posição mais conservadora à posição mais liberal, esperando, assim, que as diferenças de opiniões entre os autores abordados fiquem claras. Por fim, faremos menção à posição do Tribunal Constitucional português, órgão que tem a tarefa de "guardar a Constituição" e legitimidade no desenvolvimento do próprio direito constitucional, através da interpretação dada às normas da Constituição pelos juízes constitucionais?.

Segundo preceitua o art. $16^{\circ}, \mathrm{n}^{\circ} 2$, da CRP, "os preceitos constitucionais e legais relativos aos direitos fundamentais devem ser interpretados e integrados de harmonia com a Declaração Universal dos Direitos do Homem". Essa disposição levanta a questão do estatuto constitucional da DUDH. Embora a DUDH não apresente obrigatoriedade legal para os Estados, tornou-se a precursora na universalização dos direitos humanos, havendo menção a ela, inclusive, na $\mathrm{CRP}^{10}$. Como interpretar o preceito constitucional disposto no $\mathrm{n}^{\circ} 2$ do art. $16^{\circ}$ ?

Para o Dr. José Joaquim Gomes Canotilho e o Dr. Vital Moreira, professores da Faculdade de Direito da Universidade de Coimbra, não obstante o fato da CRP fazer menção à DUDH, como base interpretativa e integrativa dos preceitos constitucionais e legais relativos aos direitos fundamentais, o intérprete e aplicador do direito não está dispensado da necessidade de recorrer, primeiramente, à ordem constitucional. Os professores asseveram que a DUDH não assume a natureza de direito

\footnotetext{
Conforme Canotilho, que também assevera que "as decisões do Tribunal Constitucional acabam efectivamente por ter força política, não só porque a ele cabe resolver, em última instância, problemas constitucionais de especial sensibilidade política, mas também porque a sua jurisprudência produz, de facto ou de direito, uma influência determinante junto dos outros tribunais e exerce um papel condicionante do comportamento dos órgãos de direcção política". CANOTILHO, José Joaquim Gomes. Direito Constitucional e Teoria da Constituição. 7. ed. Coimbra: Almedina. p. 681.

${ }^{10}$ Para MACHADO, Jónatas Eduardo Mendes. Direito Internacional do Paradigma Clássico ao Pós-11 de Setembro. Coimbra: Coimbra Editora, 2003. p. 113, professor da Faculdade de Direito da Universidade de Coimbra, “(...) a abertura material da Constituição aos princípios fundamentais da ordem jurídica internacional contribui, só por si, para reduzir substancialmente a possibilidade de conflitos de normas, na medida em que aponta para uma interpretação mutuamente reforçada", ressaltando-se que a utilização interpretativa da DUDH não pode servir para reduzir a proteção constitucionalmente consagrada aos direitos fundamentais.
} 
constitucional, uma vez que não era desejo do legislador constituinte efetuar uma recepção da DUDH enquanto tal, mas apenas remeter para ela como parâmetro exterior. Se considerarmos alguns princípios da DUDH como normas de direito internacional (consuetudinárias ou convencionais), estas normas irão vigorar no âmbito interno como verdadeiro direito internacional, por força do art. $8^{\circ}$ da CRP, não devendo deixar de ser observada a hierarquia que lhes cabe na ordem jurídica portuguesa. Além disso, Canotilho e Moreira asseguram que essa questão é absolutamente irrelevante, visto que "a Constituição não só consumiu a Declaração sendo muitas das disposições constitucionais reprodução textual, ou quase textual, de disposição daquela - mas também inclui direitos não referidos na Declaração"11.

Continuando a exposição, fica claro que na medida em que a DUDH não vigorar na ordem jurídica portuguesa como direito internacional, ela imporse-á como princípio de interpretação constitucional em matéria de direitos fundamentais, desde que se chegue a um sentido constitucionalmente admissível, sendo vedadas interpretações em contradição com o texto da norma constitucional. Caso a interpretação dada pela CRP seja mais favorável aos direitos fundamentais do que a interpretação conforme a DUDH, é consenso dos mais recentes documentos internacionais que sejam aplicadas as normas do texto constitucional, em observância ao "princípio do nível de proteção mais elevado". Em caso de lacunas de previsão de certos direitos e de lacunas de regulamentação, a DUDH serve, igualmente, de integração entre as mesmas normas.

Os ensinamentos do Dr. José Carlos Vieira de Andrade, também professor da Faculdade de Direito da Universidade de Coimbra, avançam no sentido de afirmar que a disposição do art. $16^{\circ}, \mathrm{n}^{\circ} 2$, parece consagrarse em um "princípio de interpretação em conformidade com a Declaração Universal" 12 . O professor assevera que embora o conteúdo do referido princípio não seja manifesto, julga poder reconhecer-lhe o seguinte alcance normativo: verifica-se quais são as soluções interpretativas válidas e exclui-se as que sejam incompatíveis com os princípios constantes da DUDH, impondo-se a escolha daquela que for mais próxima do sentido da DUDH. Segundo Vieira de Andrade, a DUDH, independentemente de já vigorar no ordenamento jurídico português por consagrar preceitos de

${ }^{11}$ CANOTILHO, José Joaquim Gomes; MOREIRA, Vital. Constituição da República Portuguesa Anotada. 4. ed. Coimbra: Coimbra Editora, 2007.p. 367.

12 ANDRADE, José Carlos Vieira de. Os Direitos Fundamentais na Constituição Portuguesa de 1976. 3. ed. Coimbra: Almedina, 2007. p. 45. 
direito internacional geral, intervém na interpretação dos preceitos internos relativos aos direitos fundamentais. ${ }^{13}$ Tratando-se do preenchimento de conceitos indeterminados, a DUDH influencia a concretização do sentido dos preceitos, bem como dá uma direção valorativa que norteia a descoberta de soluções no caso de lacunas no ordenamento.

Conforme já foi visto na Introdução, Vieira de Andrade levanta a problemática questão de saber se poderíamos falar em constitucionalização dos direitos fundamentais internacionais, a partir do momento em que ocorre sua recepção e integração no sistema normativo constitucional, e indaga sobre a aplicação - ou não - do mesmo regime jurídico e acerca da dignidade constitucional que esses direitos fundamentais internacionais poderiam assumir. Assim, verificamos que embora o ilustre constitucionalista assevere, através de uma nota de rodapé ${ }^{14}$, lhe parecer, quando o $\mathrm{n}^{\circ} 2$ do art. $16^{\circ}$ remete para a DUDH, para efeitos de integração dos preceitos constitucionais nessa matéria, estar a constitucionalizar os direitos fundamentais que eventualmente resultem de princípios contidos na DUDH, e de não refutar a tese de que a "afirmação constitucional de analogia de substância entre os direitos fundamentais expressamente enumerados ou previstos e outros eventualmente constantes de leis e normas internacionais deveria corresponder uma identidade de regime", ele deixa claro que um entendimento dessa amplitude não resulta claramente do texto e que isso seria dificilmente aceitável "no contexto de uma tradição de rigidez constitucional em que a forma continua a ter um peso determinante".

13 “(...) A nossa lei fundamental confia à Declaração Universal dos Direitos do Homem um papel de relevo na interpretação e integração dos preceitos relativos aos direitos fundamentais. Ao fazê-lo, não tem certamente por objectivo a descoberta de uma solução eficaz para um problema de técnica jurídica, pois que tal não justificariam nem a clareza nem a completude da Declaração Universal, sobretudo se comparadas com outros instrumentos mais acabados (p. ex., os Pactos Internacionais das Nações Unidas ou a Convenção Européia). Também é evidente que não se trata apenas de afinar as normas internas pelas concepções dominantes na comunidade internacional, na perspectiva de uma 'uniformização normativa': não seria este um meio adequado para o fazer e não é crível que fosse essa a intenção num sistema que não abdica da superioridade do direito constitucional interno sobre o direito internacional. Pretende-se, sim, proclamar a subordinação do catálogo interno de direitos fundamentais a um principio de valor que transcende a vontade política dos Estados: a 'dignidade inerente a todos os membros da família humana', que é 'fundamento da liberdade, da justiça e da paz no mundo', como se lê no Preâmbulo da Declaração Universal. A Declaração Universal, que consagra esse valor do Homem como 'ideal comum a todos os povos e nações', é, por essa boa razão, escolhida como factor de unidade na interpretação do conjunto dos direitos fundamentais. Só que essa trans-estadualidade, que em primeira linha se crisma na remissão do $n^{\circ} 2$ do artigo $16^{\circ}$, é afinal, do mesmo modo, um sinal exterior da indicação do valor da pessoa humana como referente necessário para a compreensão dos preceitos relativos aos direitos fundamentais". ANDRADE, José Carlos Vieira de. Os Direitos Fundamentais na Constituição Portuguesa de 1976. 3. ed. Coimbra: Almedina, 2007. p. 47.

${ }^{14}$ Ibidem., p. 78. 
A eficácia no ordenamento jurídico português da declaração universal dos direitos 51 do homem

Em sentido completamente divergente de Gomes Canotilho e Moreira, assim como de Vieira de Andrade, teremos o posicionamento do Dr. Jorge Miranda, professor catedrático das Faculdades de Direito da Universidade de Lisboa e da Universidade Católica Portuguesa, que conclui, a partir da análise do $\mathrm{n}^{\circ} 2$ do art. $16^{\circ}$, que a DUDH ficou a fazer parte integrante da Constituição formal (e material) portuguesa e de que os seus princípios, como elementos essenciais da idéia de Direito, estendem a sua influência a todas as normas constitucionais e a toda ordem jurídica interna. Não há subordinação dos preceitos da DUDH à CRP, mas, pelo contrário, ambas são conjugadas na esfera dos direitos fundamentais, em uma "necessária harmonia valorativa"15. Quando a CRP deixa expressa a recepção da DUDH no art. $16^{\circ}, \mathrm{n}^{\circ} 2$, ela está recepcionando formalmente a DUDH. Não se trata, pois, de uma norma de recepção material.

Miranda concorda que, da DUDH pode-se extrair princípios gerais do Direito Internacional e que eles devem ser aplicados sempre no ordenamento jurídico interno, seja através da cláusula de recepção do Direito Internacional geral ou comum (art. $8^{\circ}, \mathrm{n}^{\circ} 1$ ), seja através da

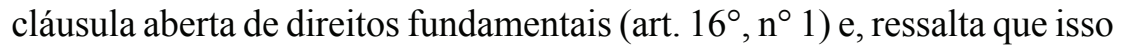
faz com que os artigos ou proposições da DUDH sejam enquadrados na categoria de princípios constitucionais, da mesma forma como acontece com aqueles inscritos no preâmbulo da CRP.

Entretanto, ao mesmo tempo em que Miranda recepciona formalmente as normas da DUDH e não as subordina à CRP, ele assevera que em caso de contradição de qualquer norma constitucional originária e não superveniente com a DUDH, aí não funcionará a recepção à Declaração prevista no art. $16^{\circ}, \mathrm{n}^{\circ} 2$, visto que a recepção opera no âmbito da Constituição. Só assim não ocorrerá quando estiverem em causa princípios da Declaração que são jus cogens ${ }^{16}$, mas estes prevalecem por si próprios, e não por força do art. $16^{\circ}, \mathrm{n}^{\circ} 2$. Da mesma forma, jamais poderia ser invocada a DUDH para impedir a aplicação de norma constitucional mais

15 MIRANDA, Jorge. Manual de Direito Constitucional. 5. ed. Coimbra: Coimbra Editora, 2003.p. 39.

16 Segundo definição de Pereira e Quadros, sendo o Direito Internacional geral ou comum um Direito Internacional imperativo, diz-se que ele é “jus cogens”. PEREIRA, André Gonçalves; QUADROS, Fausto de. Manual de Direito Internacional Público. 3. ed. Coimbra: Almedina, 1993. p. 118. No mesmo sentido, Soares traz em sua obra que "o artigo $53^{\circ}$ da citada Convenção de Viena define a norma de ius cogens como 'a que for aceite e reconhecida pela comunidade internacional dos Estados no seu conjunto como norma à qual nenhuma derrogação é permitida e que só pode ser modificada por uma norma de direito internacional da mesma natureza'. Estas normas não podem, portanto, ser derrogadas nem pode a sua aplicação ser suspensa quer a título de reciprocidade, quer a título de represálias”. SOARES, Albino de Azevedo. Lições de Direito Internacional Público. 4. ed. Coimbra: Coimbra Editora, 1988. p. 115. 
benéfica aos direitos fundamentais. " $\mathrm{O}$ art. $16^{\circ}, \mathrm{n}^{\circ} 2$, serve para reforçar a consistência e alargar o âmbito dos direitos, não para os diminuir ou restringir". ${ }^{17}$

Assim, no momento em que ocorrer contradição entre as normas da CRP e os princípios da DUDH, deve-se verificar se a norma constitucional é originária ou proveniente de revisão e, se o princípio da DUDH é de jus cogens ou não. No primeiro caso, sendo a norma constitucional originária, nunca haverá inconstitucionalidade. A contradição com o jus cogens (por definição supraconstitucional) não opera a inconstitucionalidade e se o princípio não for de jus cogens, ocorrerá a retração do alcance da DUDH: a norma constitucional (a considerar especial ou excepcional e a ser interpretada restritivamente) subtrai ao domínio da DUDH determinada matéria ou zona de matéria entre todas que nela recaem. Já se a norma constitucional for proveniente de revisão, o fenômeno reconduz-se a inconstitucionalidade, visto ser o poder de revisão constitucional um poder constituído, subordinado aos princípios fundamentais da Constituição; e, indubitavelmente, a DUDH incorpora alguns desses princípios, verdadeiros limites materiais de revisão, mesmo para além das alíneas "d" e "e" do art. $288 .{ }^{18}$

Já para o Dr. Afonso Rodrigues Queiró, antigo professor catedrático da Faculdade de Direito da Universidade de Coimbra, já falecido, sempre que falarmos em Constituição como fonte de direito administrativo, devemos entendê-la, na parte relacionada aos direitos fundamentais, interpretada e integrada harmonicamente com a DUDH. Todavia, a partir do momento em que a DUDH tem o poder de decidir qual a interpretação que dará aos preceitos constitucionais relativos aos direitos fundamentais, ela adquire uma força jurídica superior à da própria Constituição enquanto interpretada sem o subsídio desta Declaração.

Assim, Queiró assevera que a DUDH é, sem necessidade de nenhum outro ato de incorporação, direito constitucional positivo português, no que tange a direitos fundamentais, na medida em que, nesta matéria, o conteúdo da DUDH for mais abrangente do que o conteúdo da CRP. Em caso de conflito entre as normas da Declaração e da Lei Fundamental escrita portuguesa, deve-se dar preferência à DUDH, pelo menos onde ela seja mais aberta, generosa e liberal do que a CRP, visto que o "legislador

\footnotetext{
${ }^{17}$ MIRANDA, Jorge. Manual de Direito Constitucional. p. 41.

${ }^{18}$ MEDEIROS, Rui; MIRANDA, Jorge. Constituição Portuguesa Anotada. Tomo 1 - Introdução Geral - Preâmbulo - Artigos $1^{\circ}$ ao $79^{\circ}$. Coimbra: Coimbra Editora, 2005. p. 140-142.
} 
constituinte não terá certamente querido colidir com a Declaração, ficando atrás desta em matéria de direitos fundamentais" $" 19$.

Dr. Paulo Otero, professor da Faculdade de Direito da Universidade de Lisboa, vai muito mais longe do que Queiró, assegurando que através do art. $16^{\circ}, \mathrm{n}^{\circ} 2$, a CRP se auto-subordina à DUDH a nível interpretativo, em matéria de direitos fundamentais, daí decorrendo o valor supraconstitucional da DUDH, mesmo que seja a Carta Magna o fundamento da vigência da Declaração no ordenamento jurídico português. Para Otero, mesmo que a interpretação, conforme a DUDH, seja menos favorável do que a mera interpretação de normas da CRP prevalecerá a interpretação menos favorável. ${ }^{20} \mathrm{Com}$ a aceitação da existência de contradições entre a DUDH e a CRP, com prevalência daquela, o professor quer demonstrar que existem casos de inconstitucionalidade de normas constitucionais. ${ }^{21}$

Os Drs. André Gonçalves Pereira e Fausto de Quadros, também professores da Faculdade de Direito da Universidade de Lisboa, acompanham o posicionamento de Otero, no sentido de asseverar que o Direito Internacional geral ou comum ocupa um grau supraconstitucional. Para eles, quando a CRP dispõe que os preceitos constitucionais relativos aos direitos fundamentais devem ser interpretados e integrados de harmonia com a DUDH, está conferindo àquela Declaração um nível hierárquico superior ao da Constituição na ordem interna portuguesa. Além disso, visto ser o Direito Internacional geral ou comum um Direito Internacional imperativo, ou seja, jus cogens, não se vê como é que uma norma internacional pode ser imperativa para determinado Estado se não houver sua prevalência sobre todas as suas fontes de Direito interno, abrangendo a própria Constituição. ${ }^{22}$

Apesar dos diversos posicionamentos verificados na doutrina acerca da eficácia da DUDH no ordenamento jurídico português, uns mais conservadores, outros mais liberais, conforme discorremos nas linhas anteriores, encontramos no Tribunal Constitucional português,

${ }^{19}$ QUEIRÓ, Afonso Rodrigues. Lições de Direito Administrativo. Obra policopiada. Coimbra, 1976. p. 326.

${ }^{20}$ Não concordo com essa posição, assim como discordam, também, Dr. Gomes Canotilho, Dr. Vital Moreira, Dr. Jorge Miranda, Dr. Afonso Queiró, Dr. José Carlos Vieira de Andrade e Dr. José Manuel Cardoso da Costa.

${ }^{21}$ OTERO, Paulo. Declaração Universal dos Direitos do Homem e Constituição: a inconstitucionalidade de normas constitucionais. In: O Direito, 1990. p. 603-612.

${ }^{22}$ PEREIRA, André Gonçalves; QUADROS, Fausto de. Manual de Direito Internacional Público. 3. ed. Coimbra: Almedina, 1993. p. 116-119. 
o órgão "guardião da Constituição" e a quem compete, efetivamente, a interpretação das normas expressas na Carta Magna pelos juízes constitucionais, uma posição mais reservada, que concede uma eficácia interpretativa e integrativa auxiliar à DUDH. A título exemplificativo, no acórdão $n^{\circ} 222 / 90^{23}$, vemos que a DUDH deve servir de horizonte interpretativo ao texto constitucional e, no acórdão $n^{\circ} 678 / 98^{24}$, que as normas da DUDH seriam unicamente convocáveis se e na medida em que ajudassem a interpretar e integrar os preceitos e princípios da CRP atinentes a direitos fundamentais, caso essas interpretações e integração se mostrassem necessárias.

Para o Dr. José Manuel Moreira Cardoso da Costa, ex-presidente do Tribunal Constitucional português (1989-2003) e professor da Faculdade de Direito da Universidade de Coimbra, em seus ensinamentos proferidos em sala de aula ${ }^{25}$, o conteúdo da DUDH, na sua generalidade, é reconhecido como princípio internacional geral, sendo que estes princípios valem na ordem jurídica interna portuguesa por força do art. $8^{\circ}, \mathrm{n}^{\circ} 1$, da CRP. Não deve ser concedida aos preceitos da DUDH a eficácia de princípios constitucionais, por força do próprio art. $16^{\circ}, \mathrm{n}^{\circ} 2$. Interpretando a Constituição, é excessivo dizer que ela subordina a uma fonte externa a própria Constituição (supraconstitucionalidade). A DUDH foi fonte da Constituição, mas a CRP, tendo partido dela, foi muito mais além. O Tribunal Constitucional, ao assumir a DUDH como fonte auxiliar, como elemento determinante de interpretação dos direitos fundamentais, não considera a violação dos princípios da DUDH como violação de princípios constitucionais. Logo, não se pode ser levado ao Tribunal Constitucional violação de princípios da DUDH, que são na verdade violação de Direito Internacional, a não ser que seja entendida como violação de direitos constitucionais. Só haverá inconstitucionalidade quando uma norma violar princípios constitucionais.

Cardoso da Costa assevera, em sua obra "A Hierarquia das Normas Constitucionais e a sua função na protecção dos Direitos Fundamentais"26,

\footnotetext{
${ }^{23}$ Acórdão disponível em:<http://www.tribunalconstitucional.pt/tc/acordaos/19900222.html.> Acesso em: 14 dez. 2007.

${ }^{24}$ Acórdão disponível em: <http://www.tribunalconstitucional.pt/tc/acordaos/19980678.html. > Acesso em: 14 dez. 2007.

${ }^{25}$ Aulas ministradas no curso de Mestrado da Faculdade de Direito da Universidade de Coimbra, na disciplina "Direitos Fundamentais", turma 2007/2008.

${ }^{26}$ COSTA, José Manuel Moreira Cardoso da. A Hierarquia das Normas Constitucionais e a sua função na protecção dos Direitos Fundamentais. Lisboa: Mirandela \& Cia (Irmão) Ltda., 1990. p. $7-8 ; 14$.
} 
que o legislador constituinte teve o cuidado de elaborar um vasto catálogo de direitos fundamentais, o qual integra a Parte I da CRP, intitulada dos "Direitos e deveres fundamentais". Segundo o professor, trata-se de um exaustivo catálogo de direitos, em que se recolhem os contributos não só da tradição portuguesa anterior, como ainda de diplomas congêneres estrangeiros, e também de documentos internacionais sobre a matéria, em especial a DUDH. Mas trata-se, não obstante esse seu caráter exaustivo, de um catálogo aberto - e que não se pretende, pois, positivisticamente acabado -, já que a CRP não deixa de ressalvar que os direitos nela consagrados "não excluem quaisquer outros constantes das leis e das regras aplicáveis de direito internacional" (artigo $16^{\circ}, \mathrm{n}^{\circ} 1$ ) e, além disso, eleva a DUDH a padrão interpretativo e integrador dos preceitos constitucionais e legais relativos aos direitos fundamentais (artigo $16^{\circ}, \mathrm{n}^{\circ} 2$ ).

O autor enfatiza esse ponto da "abertura" do catálogo, pois ele não só denota um entendimento da categoria "direitos fundamentais" como sendo algo mais amplo do que a categoria "direitos constitucionais" (os direitos formalmente inseridos no texto da Constituição), como implica uma caracterização "material" daquela primeira categoria - a qual parece só poder residir na "essencialidade" que a consciência jurídica coletiva atribua a determinados direitos, enquanto exigência da própria dignidade da pessoa. Continuando sua exposição, vemos que embora a Constituição pressuponha, quanto aos direitos, liberdades e garantias, que o respectivo conteúdo e extensão encontram-se nela mesma definida, não deixa a sua "materialização" de exigir dos operadores jurídicos, em particular do Tribunal Constitucional, uma mais ou menos ampla e delicada atividade interpretativa dos correspondentes preceitos constitucionais.

\section{Considerações finais}

Após discorrermos sobre a eficácia no ordenamento jurídico português da DUDH e verificarmos os diversos posicionamentos doutrinários existentes, encontramos uns bem conservadores, como é o caso de Gomes Canotilho e Vital Moreira, que não atribuem aos preceitos da DUDH a natureza de direitos constitucionais, vendo-os como princípios de interpretação constitucional em matéria de direitos fundamentais e não estando o intérprete e aplicador do direito dispensado da necessidade de recorrer, primeiramente, à ordem constitucional, assim como deparamonos com posições muito mais "arrojadas" - e a meu ver excessivas -, como a de Paulo Otero, que assevera que a CRP se auto-subordina à DUDH a 
nível interpretativo, em matéria de direitos fundamentais, daí decorrendo o valor supraconstitucional da DUDH e que defende a tese de que, mesmo que a interpretação conforme a DUDH seja menos favorável do que a mera interpretação de normas da Constituição, prevalecerá a interpretação menos favorável.

Dessa forma, constatamos que há diversos modos de entender a recepção da DUDH pela CRP, propiciando discussões acerca da hierarquia das fontes normativas que em Portugal se estabelece: seria desejo do legislador constituinte apenas que os preceitos constitucionais e legais relativos aos direitos fundamentais fossem interpretados e integrados de harmonia com a DUDH, conforme está, de fato, expresso no texto da Constituição, ou seria sua vontade equiparar os princípios expressos na DUDH com os direitos formalmente inseridos no texto da CRP, constitucionalizando-os? Em um sentido ainda mais liberal, não teria o legislador constituinte a intenção de outorgar aos princípios da DUDH um valor supraconstitucional, colocando-os num nível hierarquicamente superior ao da própria Carta Magna portuguesa? Apesar desses debates infinitos e de não ter ocorrido qualquer acordo entre os vários pontos de vista doutrinários quanto à intensidade da relevância constitucional da DUDH, uma coisa é certa: a DUDH tem um grande relevo constitucional, visto estar mencionada no próprio texto da CRP. Assim sendo, de uma forma ou outra, a partir do momento em que a CRP deixa expresso no art. $16^{\circ}, \mathrm{n}^{\circ} 2$, que "os preceitos constitucionais e legais relativos aos direitos fundamentais devem ser interpretados e integrados de harmonia com a Declaração Universal dos Direitos do Homem", ela está admitindo que a Declaração "possa ombrear, nalguns dos seus aspectos, com a disciplina constante do estalão supremo do ordenamento jurídico-positivo português"27.

Em minha opinião, filio-me ao posicionamento de Gomes Canotilho e Vital Moreira, por também crer que o intérprete e aplicador do direito devam recorrer, primeiramente, à ordem constitucional; que a DUDH não assume a natureza de direito constitucional; que na medida em que a DUDH não vigorar na ordem jurídica portuguesa como direito internacional, ela imporse-á como princípio de interpretação constitucional em matéria de direitos fundamentais, desde que se chegue a um sentido constitucionalmente admissível; que caso a interpretação dada pela CRP seja mais favorável aos direitos fundamentais do que a interpretação dada pela DUDH, a interpretação da Constituição deva ser aplicada.

${ }^{27}$ GOUVEIA, Jorge Bacelar. A Declaração Universal dos Direitos do Homem e a Constituição Portuguesa. In: Revista de Informação Legislativa, Brasília, ano 35, n. 139, jul./set. 1998. p. 273. 
Ao mesmo tempo, afasto-me da posição de Vieira de Andrade, visto que o mesmo assevera que o disposto no art. $16^{\circ}, \mathrm{n}^{\circ} 2$, parece consagrar-se em um princípio interpretativo em conformidade com a DUDH, devendo-se verificar quais são as soluções interpretativas válidas e excluindo-se as que sejam incompatíveis com os princípios constantes da DUDH. Ao final, impor-se-á a escolha daquela que for mais próxima do sentido da Declaração, o que pode contrariar, a meu ver, um sentido constitucionalmente admissível. Acredito, assim como também tem interpretado o Tribunal Constitucional português, que as normas da DUDH deveriam ser unicamente convocáveis se e na medida em que ajudassem a interpretar e integrar os preceitos e princípios da CRP atinentes a direitos fundamentais, caso essas interpretações e integração se mostrassem necessárias.

No ano de 2012, comemoramos o aniversário de sessenta e quatro anos da DUDH e parece-me que um outro fato é concreto: não sendo a DUDH um documento com força coercitiva, foi a partir dela que se começou a ver que a situação e o tratamento dos indivíduos não era um assunto interno do Estado respectivo, mas algo que interessava a toda comunidade internacional. O Estado português, a partir do momento em que faz a inserção da DUDH no texto de sua CRP, mostra todo o seu empenho em proteger os direitos do homem, o que logicamente repercute positivamente na esfera universal.

\section{La eficacia en el ordenamiento jurídico portugués de la Decla- ración Universal de los Derechos Humanos}

Resumen: El objetivo de este artículo es analizar la eficacia de la Declaración Universal de los Derechos Humanos (DUDH) en el ordenamiento jurídico portugués, presentándose desde la posición doctrinaria más conservadora - que no atribuye a los preceptos de la DUDH la naturaleza de derechos constitucionales -, hasta la posición doctrinaria más liberal - que atribuye a la DUDH un valor supraconstitucional. Al final, se expone la posición del Tribunal Constitucional portugués, organismo que tiene legitimidad en el desarrollo del propio derecho constitucional, a través de la interpretación dada a las normas de la Constitución por los jueces constitucionales.

Palabras clave: Eficacia en el ordenamiento jurídico portugués de la Declaración Universal de los Derechos Humanos. Divergencia doctrinaria y posición del Tribunal Constitucional. Estatuto constitucional de la DUDH. 


\section{REFERÊNCIAS}

Acórdão $\mathrm{n}^{\circ}$ 222/90 do Tribunal Constitucional português. Disponível em: <http://www.tribunalconstitucional.pt/tc/acordaos/19900222.html >. Acesso em: 14 dez. 2007.

Acórdão n ${ }^{\circ}$ 678/98 do Tribunal Constitucional português. Disponível em: <http://www.tribunalconstitucional.pt/tc/acordaos/19980678.html.> Acesso em: 14 dez. 2007.

ANDRADE, José Carlos Vieira de. Os Direitos Fundamentais na Constituição Portuguesa de 1976. 3. ed. Coimbra: Almedina, 2007.

ASSEMBLÉIA da República. Declaração Universal dos Direitos do Homem - 50 anos. Santo Tirso/Portugal: Norprint, 1998.

BROWNLIE, Ian. Princípios de Direito Internacional Público. Lisboa: Fundação Calouste Gulbenkian, 1997.

CANOTILHO, José Joaquim Gomes. Direito Constitucional e Teoria da Constituição. 7. ed. Coimbra: Almedina.

CANOTILHO, José Joaquim Gomes; MOREIRA, Vital. Constituição da República Portuguesa - Lei do Tribunal Constitucional. 8. ed. Coimbra: Coimbra Editora, 2005.

. Constituição da República Portuguesa Anotada. 4. ed. Coimbra: Coimbra Editora, 2007. v. 1.

COSTA, José Manuel Moreira Cardoso da. A Hierarquia das Normas Constitucionais e a sua função na protecção dos Direitos Fundamentais. Lisboa: Mirandela \& Cia (Irmão) Ltda., 1990.

. A Jurisdição Constitucional em Portugal. 3. ed. Coimbra: Almedina, 2007.

GOUVEIA, Jorge Bacelar. A Declaração Universal dos Direitos do Homem e a Constituição Portuguesa. In: Revista de Informação Legislativa, Brasília, ano 35, n. 139, jul./set. 1998. 
A eficácia no ordenamento jurídico português da declaração universal dos direitos 59 do homem

MACHADO, Jónatas Eduardo Mendes. Direito Internacional do Paradigma Clássico ao Pós-11 de Setembro. Coimbra: Coimbra Editora, 2003.

MEDEIROS, Rui; MIRANDA, Jorge. Constituição Portuguesa Anotada. Tomo 1 - Introdução Geral - Preâmbulo - Artigos $1^{\circ}$ ao $79^{\circ}$. Coimbra: Coimbra Editora, 2005.

MIRANDA, Jorge. A Constituição e a Democracia Portuguesa. Disponível em: $<$ http://www.25abril.org/docs/congresso/democracia/01.01-Jorge\%20Miranda.pdf.> Acesso em: 10 dez. 2007.

. Manual de Direito Constitucional. 5. ed. Coimbra: Coimbra Editora, 2003. v. 2.

OTERO, Paulo. Declaração Universal dos Direitos do Homem e Constituição: a inconstitucionalidade de normas constitucionais. In: O Direito, 1990.

PELLET, Alain [et al.] Direito Internacional Público. 2. ed. Lisboa: Fundação Calouste Gulbenkian, 2003.

PEREIRA, André Gonçalves; QUADROS, Fausto de. Manual de Direito Internacional Público. 3. ed. Coimbra: Almedina, 1993.

QUEIRÓ, Afonso Rodrigues. Lições de Direito Administrativo. Coimbra, 1976. v. 1.

SOARES, Albino de Azevedo. Lições de Direito Internacional Público. 4. ed. Coimbra: Coimbra Editora, 1988.

Recebido: março/2010. Aprovado: abri1/2012 